\title{
Resident peritoneal macrophages and mast cells are important cellular sites of COX-1 and COX-2 activity during acute peritoneal inflammation
}

\author{
Elzbieta Kolaczkowska ${ }^{1}$, Anna Goldys ${ }^{1}$, Elzbieta Kozakiewicz ${ }^{1}$, Monika Lelito ${ }^{1}$, \\ Barbara Plytycz ${ }^{1}$, Nico van Rooijen ${ }^{2}$ and Bernd Arnold ${ }^{3}$ \\ ${ }^{1}$ Department of Evolutionary Immunobiology, Institute of Zoology, Jagiellonian University, Kraków, Poland \\ ${ }^{2}$ Department of Molecular Cell Biology, Faculty of Medicine, Vrije Universiteit, Amsterdam, the Netherlands \\ ${ }^{3}$ Laboratory for Molecular Immunology, German Cancer Research Center, Heidelberg, Germany
}

Received: 2008.10.07, Accepted: 2009.04.29, Published online: 2009.11.03

(c) L. Hirszfeld Institute of Immunology and Experimental Therapy, Wrocław, Poland 2009

\begin{abstract}
Introduction: Cyclooxygenases (COXs) play important roles during inflammation. While reports on COX-2 function in inflammation preceded those on COX-1, it is now well established that both isoforms participate in this process. During inflammation, COX expression was reported in inflammatory leukocytes, but much less is known about their presence in tissue-resident leukocytes. The aim was thus to verify the expression and activity of the COX isoforms in resident peritoneal mast cells and macrophages during acute peritonitis.

Materials and Methods: Zymosan peritoneal inflammation was induced in C57BL/6J mice and COX-1 and COX-2 expression was evaluated by RT-PCR (mRNA level) and immunocytochemistry (protein level). COX activity was assessed by a specific assay and prostaglandin production by ELISA. Furthermore, some mice were selectively depleted of either peritoneal mast cells or macrophages and then COX activity was determined.

Results: The study revealed that both COXs are expressed/active at the peak of inflammation, but COX-2 predominates during resolution. The expressions of the COXs were detectable in both populations of resident peritoneal leukocytes. In peritoneal macrophages both isoforms were active even during the late phases of peritonitis and the cells significantly contributed to $\mathrm{PGE}_{2}$ and $\mathrm{PGD}_{2}$ synthesis. The most striking observation was that resident macrophages are critical for $\mathrm{PGD}_{2}$ production during the resolution of inflammation.

Conclusions: This study documents that both COX isoforms participate in all stages of acute inflammation and that tissueresident leukocytes, especially macrophages, are important sites of COX-1/COX-2 expression and prostaglandin synthesis.
\end{abstract}

Key words: cyclooxygenase, peritoneal inflammation, prostaglandins, resident peritoneal leukocytes.

Abbreviations: ANOVA - one-way analysis of variance, cDNA - complementary deoxyribonucleic acid, $\mathrm{Cl}_{2} \mathrm{MDP}_{-}$ dichloromethylene diphosphonate, DAB - 3',3'-diaminobenzidine tetrahydrochloride, EDTA - ethylenediaminetetraacetic acid, ELISA - enzyme-linked immunosorbent assay, HPRT - hypoxanthine phosphoribosyltransferase, IgG - immunoglobulin G, IL-10 - interleukin 10, MCx - mast cell-depleted mice, M $\phi x$ - macrophage-depleted mice, mRNA - messenger ribonucleic acid, TMPD - oxidized N,N,N',N'-tetramethyl-p-phenylenediamine, Tris-HCl - tris(hydroxymethyl)aminomethane and concentrated hydrochloric acid, $\mathrm{PGD}_{2}-$ prostaglandin $\mathrm{D}_{2}, \mathrm{PGE}_{2}-$ prostaglandin $\mathrm{E}_{2}, \mathrm{PGI}_{2}-$ prostaglandin $\mathrm{I}_{2}, \mathrm{RT}_{-}$ -PCR - reverse transcriptase polymerase chain reaction, SD - standard deviation, PTL - total peritoneal leukocyte.

Corresponding author: Elżbieta Kołaczkowska, Department of Evolutionary Immunobiology, Institute of Zoology, Jagiellonian University, Ingardena 6, 30-060 Kraków, Poland, tel.: +48 12-6632663, fax: +48 12-6343716, e-mail: ela.kolaczkowska@uj.edu.pl

\section{INTRODUCTION}

An acute inflammatory response is driven by numerous mediators of different origin that induce, control, or terminate its subsequent phases from the onset of inflammation to its resolution (Majno and Joris 2004). Of these mediators, prostaglandins play a pivotal role at all stages (Miller 2006; Simmons et al. 2004). Prosta- 
glandins are products of cyclooxygenase (COX) enzymatic activity and can be functionally divided into proand anti-inflammatory (Miller 2006). The former group includes prostaglandin $(\mathrm{PG}) \mathrm{E}_{2}$, which promotes the development of an inflammatory response, while the latter inhibits inflammatory activities and includes anti-inflammatory prostaglandins such as $\mathrm{PGD}_{2}$ and its metabolites, cyclopentenone prostaglandins of the J-series (Sheibanie et al. 2007; Straus et al. 2000).

Prostaglandins were discovered in the 1930s, and in 1971 it was shown that COX is the enzyme that catalyses the biosynthesis of prostaglandins (Hamberg and Samuelsson 1973; Vane 1971). Twenty years later it was demonstrated that COX actually exists in two isoforms, COX-1 and COX-2 (Fu et al. 1990; Masferrer et al. 1990; Miller 2006). From the discovery of COX-2 to the beginning of the new millennium, the dogma was that the constitutive COX-1 plays a role in physiological processes, while the inducible COX-2 is involved in inflammation, cancer, and other pathological processes (Simmons et al. 2004; Willoughby et al. 2000). However, the pattern of COX expression has recently been reevaluated upon the discovery of a constitutive expression of COX-2 in, for example, the kidney, brain, female reproductive system, and bones [for a review see (Warner and Mitchell 2004)]. COX-1 expression was also shown to be modulated when homeostasis becomes unbalanced; for example, some studies on COX-1- and COX-2-deficient mice presented evidence that COX-1 might also be involved in inflammation (Langenbach et al. 1995; Morham et al. 1995).

A role for COX-1 in early vascular changes was also shown during acute experimental peritoneal inflammation induced by zymosan, a polysaccharide component of Saccharomyces cerevisiae (Kolaczkowska et al. 2002; Rao et al. 1994). The study revealed that the early COX-1-derived prostaglandins $\left(\mathrm{PGE}_{2}, \mathrm{PGI}_{2}\right)$ originated from resident peritoneal leukocytes, i.e. mast cells and macrophages (Kolaczkowska et al. 2002; Rao et al. 1994). These leukocyte populations, although often neglected, are critical not only for the onset of peritoneal inflammation, but also for its later phases, including the resolution of the inflammatory reaction (Ajuebor et al. 1999; Kolaczkowska et al. 2007; Kolaczkowska et al. 2002). Therefore the aim of this study was to evaluate the involvement of tissue-resident leukocytes in COX-1 and COX-2 activity during all stages of zymosan peritoneal inflammation. The results indicate that resident peritoneal mast cells and, especially, macrophages are important cellular sites of COX activity also during its late stages.

\section{MATERIALS AND METHODS}

\section{Mice}

Male $\mathrm{C} 57 \mathrm{Bl} / 6$ mice (6-8 weeks old, $24-27 \mathrm{~g}$ body weight) were purchased from the animal-breeding unit of the Collegium Medicum (Krakow, Poland). The mice were kept at a room temperature of $20 \pm 2^{\circ} \mathrm{C}$, and a 12 -h:12-h light/dark cycle. The mice were fed on a commercial pellet diet and tap water was available ad libitum. The animals were housed 4-5 mice per cage in polycarbonate cages on bedding containing dust-free, microbiologically clean, soft wood granules. All in vivo experiments were approved by the Local Ethics Committee.

\section{Peritonitis}

Peritoneal inflammation was induced as described previously (Doherty et al. 1985; Kolaczkowska et al. 2001b). Zymosan A (Sigma-Aldrich, St Louis, MO, USA) was freshly prepared $(2 \mathrm{mg} / \mathrm{ml})$ in sterile $0.9 \%$ w/v saline and $0.5 \mathrm{ml}$ was injected i.p. Animals were killed by decapitation at the selected time points. The peritoneal cavity was lavaged with $1 \mathrm{ml}$ of saline and after $30 \mathrm{sec}$ of gentle manual massage the exudate was retrieved and centrifuged at $400 \times \mathrm{g}$ for $10 \mathrm{~min}$. The cells were counted with a hemocytometer following staining with Turk's solution $(0.01 \%$ crystal violet in $3 \%$ acetic acid) as described previously (Kolaczkowska et al. $2001 \mathrm{~b}$ ). The supernatants were frozen at $-20^{\circ} \mathrm{C}$ prior to analysis while the cell pellets were further treated as described below in "COX activity assay"

\section{Cell depletion}

Resident peritoneal mast cells. Functional resident peritoneal mast cells were removed by a single i.p. injection of compound 48/80 (Sigma-Aldrich) at a dose of 1.2 $\mathrm{mg} / \mathrm{kg}(100 \mu \mathrm{l} / \mathrm{mouse}) 72 \mathrm{~h}$ before the induction of inflammation (Das et al. 1997; Kolaczkowska et al. 2006b). Successful depletion was confirmed by a microscopic analysis of safranin O-positive peritoneal leukocytes [as described in (Kolaczkowska et al. 2001b); data not shown] collected from compound-treated and untreated mice (at time 0 ). The treatment lead to functional depletion of over $95 \%$ of mast cells $\left(1.51 \pm 0.38 \times 10^{4}\right.$ intact mast cells vs. $0.08 \pm 0.07 \times 10^{4}$ mast cells after treatment with compound 48/80).

Resident peritoneal macrophages. To deplete resident peritoneal macrophages, mice received i.p. injections of $100 \mu \mathrm{l}$ of dichloromethylene diphosphonate ( $\left.\mathrm{Cl}_{2} \mathrm{MDP}\right)$ -liposomes for three consecutive days and inflammation was induced on day 4 (Ajuebor et al. 1999; Kolaczkowska et al. 2006b; Kolaczkowska et al. 2002). Multilamellar liposomes containing $\mathrm{Cl}_{2}$ MDP-liposomes were prepared as described previously (van Rooijen and Sanders 1994). Control mice were injected with either liposomes containing phosphate buffered saline (PBS) or sterile saline (Polskie Odczynniki Chemiczne, Gliwice, Poland). $\mathrm{Cl}_{2} \mathrm{MDP}$ was a gift of Roche Diagnostics GmbH, Mannheim, Germany. Successful macrophage depletion was confirmed by an immunocytochemical analysis of Mac-3-positive peritoneal cells [as described in (Kolaczkowska et al. 2006b); data not 
shown] collected from $\mathrm{Cl}_{2} \mathrm{MDP}$-treated and untreated mice. Over $90 \%$ of macrophages were removed by $\mathrm{Cl}_{2} \mathrm{MDP}$ treatment $\left(5.98 \pm 1.32 \times 10^{6}\right.$ intact macrophages vs. $0.44 \pm 0.04 \times 10^{6}$ macrophages after treatment with the liposomes).

Whenever studies on mast cell (MCx)- or macrophage $(\mathrm{M} \phi \mathrm{x})$-depleted mice are discussed or shown, animals with normal resident peritoneal leukocyte populations are described as controls (ctr).

\section{Quantitative RT-PCR analysis}

The analysis was performed as described previously (Kolaczkowska et al. 2006a; Kolaczkowska et al. 2006b). Briefly, total RNA from cells collected from intact or inflamed peritoneum was isolated using the QIAshredder and RNeasy Mini Kit (QIAGEN, Valenica, CA, USA). The amount and purity of the total RNA was determined by spectrophotometry (GENESYS $10 \mathrm{UV}$; Thermo Electron Corporation, Waltham, MA, USA) at $260 \mathrm{~nm}$. RNA was translated into single-stranded cDNA using the Superscript cDNASynthesis kit (Invitrogen, Carlsbad, CA, USA) and random hexamers (Amersham Biosciences, Piscataway, NJ, USA). Relative gene expression levels were determined using real-time PCR TaqMan technology (GeneAmp 5700 Sequence Detection System; Applied Biosystems, Foster City, CA, USA) and SYBR green (Eurogentec, Liege, Belgium) incorporation. The mouse hypoxanthine phosphoribosyltransferase (HPRT) gene served as an internal standard. The following mouse-specific primers (5' to 3 ') were used:

COX-1: CACCAGTCAATCCCTGTTGTTACT, GGTAGTTGTCGAGGCCAAAGC;

COX-2: GAACCGCATTGCCTCTGAA, TTGTTGTAGAGAAACTGTTTAAAGCTGTAC.

\section{Immunocytochemical detection of $\mathrm{COX}-1$ and $\mathrm{COX}-2$}

Cytospins containing $5 \times 10^{5}$ peritoneal leukocytes were prepared on slides coated with silicone (Sigmacote ${ }^{\circledR}$, Sigma-Aldrich) by centrifugation $(5 \mathrm{~min}$ at $1500 \mathrm{rpm}$; Hettich Universal, Tuttlingen, Germany). The cytospin preparations were immediately fixed with a methanol:acetone mixture (1:1) and stored at $-20^{\circ} \mathrm{C}$ until analysis. The immunocytochemical procedure was performed as described in detail previously (Kolaczkowska et al. 2007). The antibodies used were: for COX-1, primary rabbit anti-mouse anti-COX-1 purified antibody (Cayman Chemical, Ann Arbor, MI, USA) diluted 1:500 and secondary goat anti-rabbit immunoglobulin $\mathrm{G}$ ( $\mathrm{IgG}$ ) peroxidase-conjugated antibody (Sigma-Aldrich) diluted 1:1000, and for COX-2, purified mouse anti-mouse anti-COX-2 (BD Biosciences, San Diego, CA, USA; 1:500) and biotinylated rat anti-mouse IgG (BD Biosciences; 1:400) followed by streptavidin-peroxidase complex (BD Biosciences). In both cases the products of the reaction were visualized with 3',3'-diaminobenzidine tetrahy- drochloride (DAB; ICN Int., Basel, Switzerland) and the cells were further counterstained with Harris hematoxyline (Stamar, Dąbrowa Górnicza, Poland) to facilitate identification of positive and negative cells. Negative controls were incubated with neither primary nor secondary antibodies. The cytospine preparations were examined under a light microscope $(400 \times)$ and photographed at a magnification of $1000 \times$ (Coolpix 4500, Nikon, Tokyo, Japan). The percentages of COX-1- and COX-2-positive cells were counted with an eyepiece graticule $(20 \times 20)$. For each time point at least three cytospins were stained and analyzed, of which three to four fields were counted. The percentages of $\mathrm{COX}-1^{+}$and $\mathrm{COX}-2^{+}$cells were recalculated per total peritoneal leukocyte (PTL) numbers [a pattern of PTL kinetics was published previously: (Kolaczkowska et al. 2008a; Kolaczkowska et al. 2001b) and are shown here as absolute COX-1- or -2-positive cell numbers in the peritoneum].

\section{COX activity assay}

First the cell pellets were homogenized. For this they were resuspended in $50 \mu \mathrm{l}$ of cold buffer $(0.1 \mathrm{M}$ Tris- $\mathrm{HCl}, \mathrm{pH} 7.8$, containing $1 \mathrm{mM}$ EDTA) and centrifuged at $10,000 \times \mathrm{g}$ for $15 \mathrm{~min}$ at $4^{\circ} \mathrm{C}$. The supernatants were collected and frozen at $-80^{\circ} \mathrm{C}$ prior to assay. COX activity was then measured using a commercial COX Activity Assay (Cayman Chemical) that measures the peroxidase activity of COX. The assay was performed according to manufacturer's instructions. Briefly, the peroxidase activity was assayed colorimetrically by monitoring the appearance of oxidized N,N,N',N'-tetramethyl-p-phenylenediamine (TMPD) at $590 \mathrm{~nm}$. The activities of COX-1 and COX-2 were differentiated using the isoform-specific inhibitors DuP-697 (selective COX-2 inhibitor) and SC-560 (selective COX-1 inhibitor) according to the manufacturer's instructions. This kit also includes purified ovine COX-1 as a positive control and its activity was inhibited by SC-560, but not by DuP-697. COX activity is expressed as the rate of oxidation of TMPD in units of $\mathrm{nmol} / \mathrm{min} / \mathrm{mg}$ protein.

\section{Determination of $P G E_{2}$ and $P D E_{2}$ concentration by ELISA}

$\mathrm{PGE}_{2}$ and $\mathrm{PDE}_{2}$ levels were estimated by ELISA kits from Cayman Chemical according to the manufacturer's instructions.

\section{Statistical analysis}

All values are reported as the mean \pm SD. Kinetic changes in each parameter were analyzed by one-way analysis of variance (ANOVA) followed by post hoc Tukey's test to compare the values recorded at the individual time points with those at time 0 (in intact animals). Differences between control (ctr) and $\mathrm{M} \phi \mathrm{x}$ or $\mathrm{MCx}$ animals were analyzed by Student's $t$-test. 
Differences were considered statistically significant at $\mathrm{p} \leq 0.05$.

\section{RESULTS}

\author{
Kinetics of COX-1 and COX-2 mRNA changes \\ during zymosan peritonitis
}

Upon injection of zymosan, the levels of mRNA encoding COX-1 dropped (Fig. 1A). During the next hours the amount of COX-1 transcript fluctuated slightly (not significantly) and stayed at a low level until the 24th h of inflammation (Fig. 1A). In contrast, COX-2 mRNA levels were negligible in intact mice, but dramatically increased already $2 \mathrm{~h}$ after zymosan injection and stayed at an equally high level for the next $4 \mathrm{~h}$ (Fig. 1A). At $8 \mathrm{~h}$ of inflammation, COX-2 mRNA levels dropped radically and at $24 \mathrm{~h}$ returned to the levels detected in intact mice (Fig. 1A). The COX-1 mRNA levels were significantly higher than those of COX-2 in the untreated mice, but the opposite phenomenon was observed at $6 \mathrm{~h}$ of peritonitis.

\section{Changes in $\mathrm{COX}-1^{+}$and $\mathrm{COX}-2^{+}$peritoneal cell numbers during zymosan peritonitis}

Almost all leukocytes present in the peritoneum of the intact mice were COX-1 positive. At $4 \mathrm{~h}$ of inflammation the $\mathrm{COX}-1^{+}$counts increased, reaching maximal numbers at $8 \mathrm{~h}$, and then started to fall, reaching control levels at $24 \mathrm{~h}$ (Fig. 1B). In contrast to COX-1, only some peritoneal leukocytes present in the peritoneum of intact mice stained positively for COX-2. From the 4th $\mathrm{h}$ of peritonitis, the numbers of $\mathrm{COX}-2^{+}$leukocytes started to increase and the highest $\mathrm{COX}-2^{+}$counts were detected at $8 \mathrm{~h}$. By $24 \mathrm{~h}$ of inflammation they had returned to the levels detected in the intact animals (Fig. 1B). At 4 and $8 \mathrm{~h}$ of peritonitis there were noticeably more $\mathrm{COX}-1^{+}$than $\mathrm{COX}-2^{+}$leukocytes, while this difference was not significant at $6 \mathrm{~h}$ of peritonitis as there was considerable variation in the COX-1 signal among the mice.

Examples of immunocytochemical staining of peritoneal leukocytes for COX-1 and COX-2 are presented in Fig. 2. The staining revealed that cells carrying COX1 were much more numerous than those containing COX-2 (left vs. right column). Moreover, $\mathrm{COX}_{-1}{ }^{+}$ leukocytes were also frequent in the zymosan-untreated mice (time 0 ), in contrast to the few $\mathrm{COX}-2^{+}$cells (Fig. 2 ). The percentage of COX-positive cells recorded by immunocytochemical staining (Fig. 2) was subsequently recalculated per PTL number and the results are presented in Fig. 1B. Some indirect conclusions on the cellular sources in which COX-1 and COX-2 expression take place can be based on the data presented in Fig. 1B. In particular one can observe that almost all leukocytes expressed COX-1 protein under either physiological or inflammatory conditions. Moreover, expression of COX-
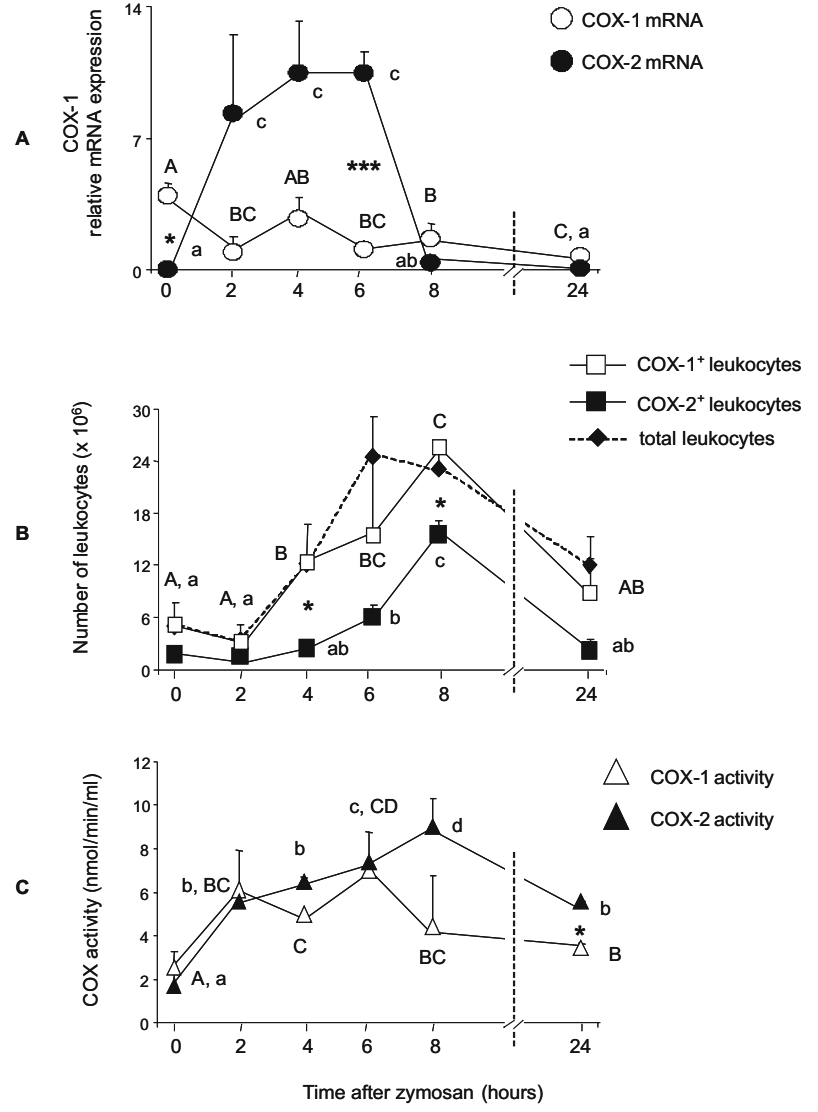

Fig. 1. Kinetic changes in COX expression and activity at the transcript and protein levels during zymosan peritonitis in mice. Mice were injected i.p. with zymosan and decapitated at the selected time points; some animals were left untreated (controls, time 0 ). Relative COX-1 and COX-2 mRNA expression was estimated in pellets of peritoneal leukocytes (A). Peritoneal lavages were used to estimate (B) the numbers of $\mathrm{COX}-1^{+}$and $\mathrm{COX}-2^{+}$peritoneal cells among all leukocytes present in the peritoneum and (C) evaluation of COX isoforms in peritoneal leukocytes. Upper case letters are used for COX-1 and lower case for COX-2. All results are shown as the mean \pm SD in groups of 3-5 mice. Mean values not sharing letters are statistically significantly different according to ANOVA $(p<0.05)$. Some differences between COX-1 and COX-2 mRNA expression are statistically significant at $0.01 \leq \mathrm{p} \leq 0.05\left(^{*}\right)$, $0.01 \geq \mathrm{p} \geq 0.001(* *), \mathrm{p} \leq 0.001(* * *)$.

1 and COX-2 might occur within the same cells, as the collective numbers of $\mathrm{COX}-1^{+}$and $\mathrm{COX}-2^{+}$cells are higher than those of PTLs (e.g. at 6-8 h). Our previous studies showed that at 6 and $24 \mathrm{~h}$ of zymosan peritonitis, each COX isoform is expressed equally in neutrophils and macrophages present in the peritoneum, without any cell-type restrictions (Kolaczkowska et al. 2009).

\section{Kinetic changes in COX-1 and -2 activities during zymosan peritonitis}

The activity of both COX isoforms was low in the untreated mice and increased upon zymosan injection (Fig. 1C). COX-1 activity enhanced during inflammation, reaching its highest values at $6 \mathrm{hrs}$, and then start- 


\section{coX-1}
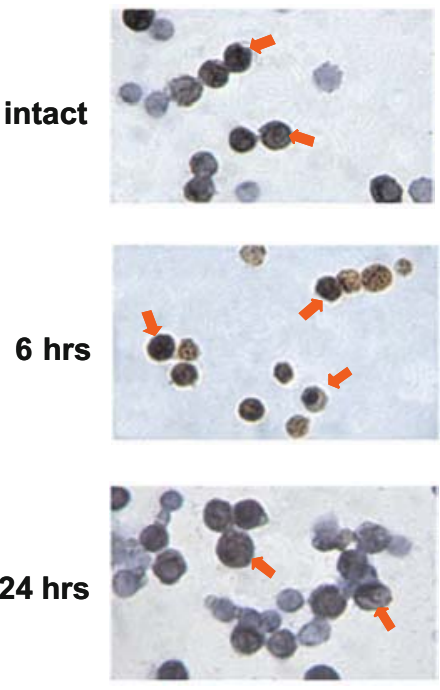

COX-2
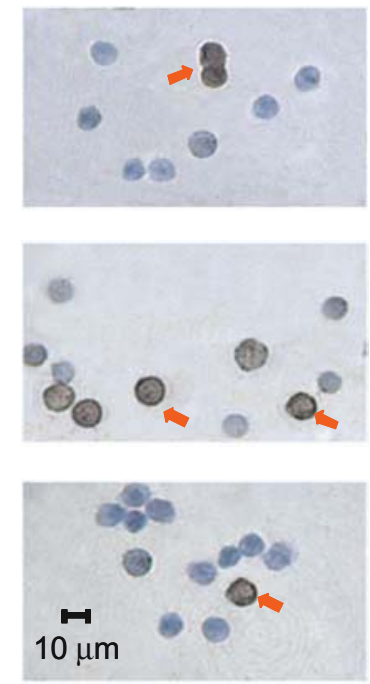

Fig. 2. Immunocytochemical detection of COX-1 and COX-2 expression in peritoneal leukocytes during zymosan peritonitis. Mice were injected i.p. with zymosan and decapitated at the selected time points; some animals were left untreated (intact, time 0 ). Examples of peritoneal leukocytes (PTLs) positive for COX-1 and COX-2 retrieved at the selected time points are marked with red arrows.

ed to drop (Fig. 1C). COX-2 activity gradually increased in the course of zymosan peritoneal inflammation, reaching maximal values at $8 \mathrm{~h}$ (Fig. 1C). At $24 \mathrm{~h}$ of peritonitis, both COX activities decreased; however, this effect was significantly stronger in the case of COX-1 than COX-2 (Fig. 1C).

\section{Levels of $\mathrm{PGE}_{2}$ and $\mathrm{PGD}_{2}$ during zymosan peritonitis}

Only negligible levels of $\mathrm{PGE}_{2}$ and $\mathrm{PGD}_{2}$ were detected in the peritoneal fluid of the intact mice (Fig. $3 \mathrm{~A}, \mathrm{~B})$. The levels of $\mathrm{PGE}_{2}$ increased upon zymosan in vivo stimulation and reached maximal values between 2 and $4 \mathrm{~h}$ (Fig. 3A). From the 6th $\mathrm{h}$ of peritonitis the $\mathrm{PGE}_{2}$ levels started to decrease and at $8 \mathrm{~h}$ they were already at the basal levels (Fig. $3 \mathrm{~A}$ ). $\mathrm{PGD}_{2}$ was already present in the peritoneal exudate at $2 \mathrm{~h}$ of inflammation and reached its highest values at $24 \mathrm{~h}$ of inflammation (Fig. 3B).

\section{Dependence of COX-1 and COX-2 activity}

on the presence of resident peritoneal macrophages and mast cells during zymosan peritonitis

The absence of either resident peritoneal macrophages or mast cells decreased COX-1 activity at every investigated time point (Fig. 4A). COX-2 activity was affected by the removal of either resident peritoneal population only at $6 \mathrm{~h}$ of inflammation, whereas in untreated mice and at $24 \mathrm{~h}$ of peritonitis only a lack of macrophages reduced it (Fig. 4B).

A
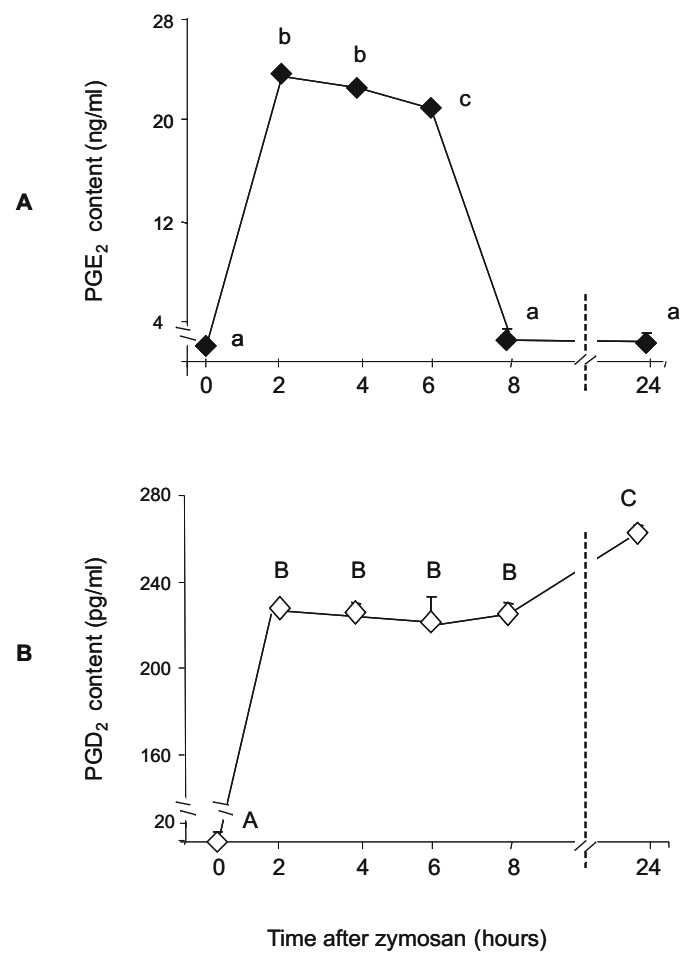

Fig. 3. Kinetic changes in prostaglandin production during zymosan peritonitis in mice. Mice were injected i.p with zymosan and decapitated at the selected time points; some animals were left untreated (controls, time 0). Content of $\mathrm{PGE}_{2}(\mathrm{~A})$ and $\mathrm{PGD}_{2}$ (B) in the peritoneal exudate was monitored. All results are shown as the mean \pm SD in groups of 3-5 mice. Mean values not sharing letters are statistically significantly different according to ANOVA $(\mathrm{p}<0.05)$.

Impact of resident peritoneal macrophages and mast cells on $P G E_{2}$ and $\mathrm{PGD}_{2}$ synthesis during zymosan peritonitis

Lack of either population weakened $\mathrm{PGE}_{2}$ production in intact mice, while at $6 \mathrm{~h}$ of inflammation only a lack of peritoneal macrophages significantly decreased its production (Fig. 5A). At $24 \mathrm{~h}$ of peritonitis, no significant changes in $\mathrm{PGE}_{2}$ were observed upon removal of any resident leukocyte population. In intact animals, $\mathrm{PGD}_{2}$ synthesis was affected by a lack of functional mast cells, but not macrophages (Fig. 5B). In contrast, at 6 and $24 \mathrm{~h}$ of inflammation, significantly reduced $\mathrm{PGD}_{2}$ production was observed only in the absence of peritoneal macrophages (Fig. 5B).

\section{DISCUSSION}

This study was performed on an experimental model of acute inflammation induced by stimulation of the peritoneum with zymosan. The model includes all the well-known hallmarks of acute inflammation: the onset of inflammation accompanied by an increase in vascular permeability $(<1 \mathrm{~h})$, the peak of inflammation reflected by neutrophil infiltration into the peritoneum (with 
A
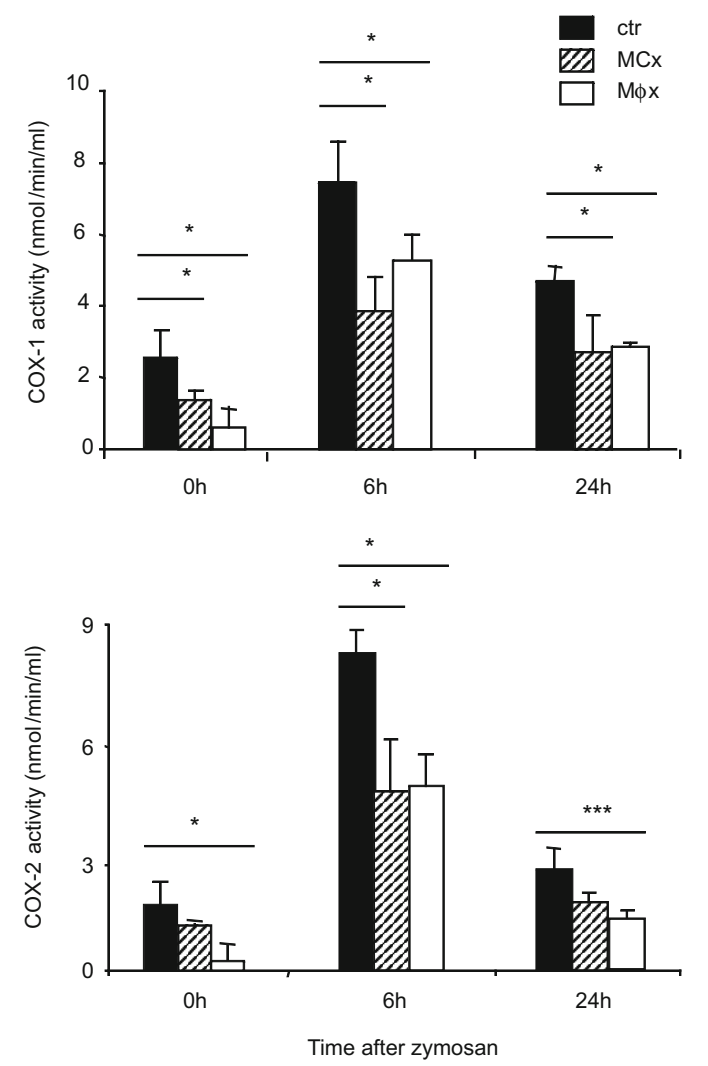

Fig. 4. Effects of peritoneal mast cell and macrophage depletion on cyclooxygenase activity during zymosan peritonitis. All animals were injected i.p with zymosan and decapitated at the selected time points. Before the induction of peritonitis, some mice were depleted of either peritoneal macrophages (M $\phi x)$ or mast cells (MCX); ctr - control mice with normal peritoneal cell populations. COX-1 (A) and COX-2 (B) activity in peritoneal leukocytes was monitored. All results are shown as the mean \pm SD in groups of 3-5 mice. Some differences are statistically significant at $0.01 \leq \mathrm{p} \leq 0.05$ $\left.{ }^{*}\right), 0.01 \geq \mathrm{p} \geq 0.001(* *), \mathrm{p} \leq 0.001(* * *)$.

highest leukocyte numbers at $6 \mathrm{~h}$ ) and the release of numerous pro-inflammatory mediators, and finally the resolution of inflammation (Ajuebor et al. 1999; Doherty et al. 1985; Kolaczkowska et al. 2006a; Kolaczkowska et al. 2001a; Kolaczkowska et al. 2007; Kolaczkowska et al. 2006b; Kolaczkowska et al. 2001b; Kolaczkowska et al. 2002). The last process is accompanied by inflammatory macrophage inflow (after $24 \mathrm{~h}$ ) and anti-inflammatory mediator synthesis.

The current report shows the whole sequence of events, from changes in COX mRNA content to the expression of the protein in leukocytes and finally COX activity evaluated by two different approaches. The study revealed that the expression of COX-1 mRNA decreases upon zymosan injection. This could be explained by an enormous demand for COX-1 protein resulting in the translation of the majority of its transcript pool. In fact, the increasing expression of COX-1 protein in leukocytes in the course of zymosan peritonitis as well as the very intensive production of prostaglandins seem to confirm this supposition. In con-
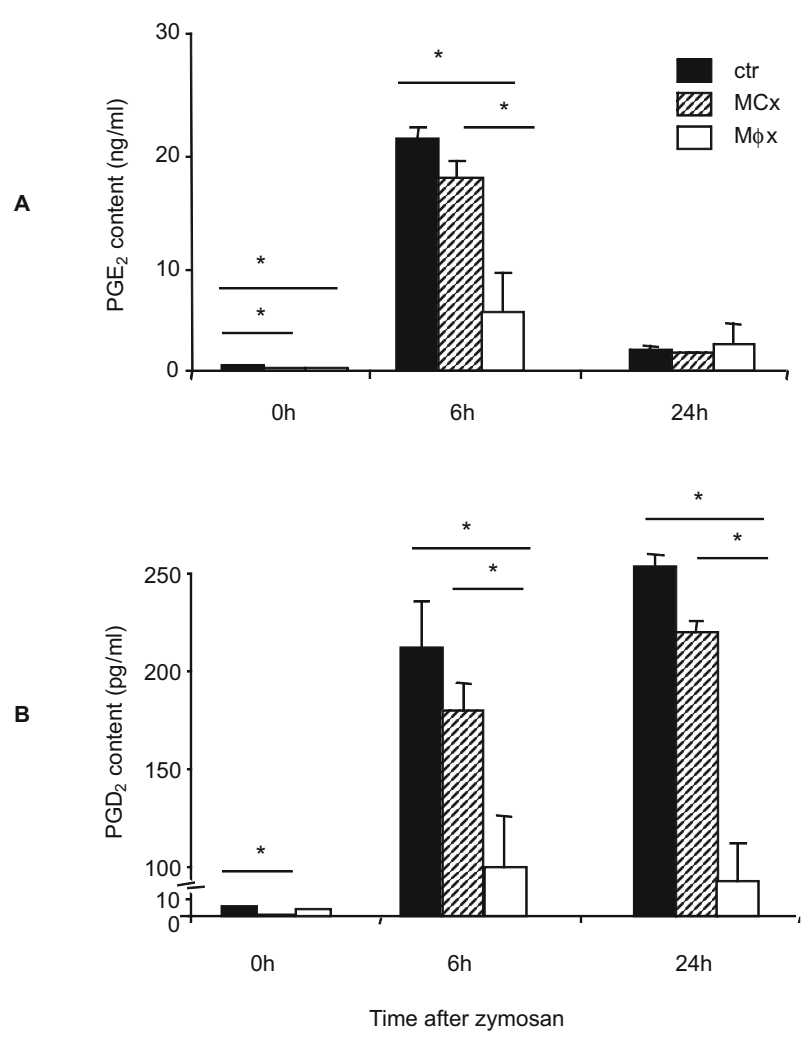

Fig. 5. Effects of peritoneal mast cell and macrophage depletion on prostaglandin production during zymosan peritonitis. All animals were injected i.p. with zymosan and decapitated at the selected time points. Before the induction of peritonitis, some mice were depleted of either peritoneal macrophages $(\mathrm{M} \phi \mathbf{x})$ or mast cells (MCX); ctr - control mice with normal peritoneal cell populations. $\mathrm{PGE}_{2}(\mathrm{~A})$ and $\mathrm{PGD}_{2}(\mathrm{~B})$ content in the peritoneal exudate was monitored. All results are shown as the mean \pm SD in groups of 3-5 mice. Some differences are statistically significant at $0.01 \leq \mathrm{p} \leq 0.05\left(^{*}\right)$.

trast, COX-2 transcript increased after zymosan administration. Similar observation was described previously with semi-quantitative PCR analysis that revealed the appearance of a weak COX-2 mRNA signal already at $30 \mathrm{~min}$ of zymosan peritonitis (Kolaczkowska et al. 2002), but here we show that the transcript levels rise further. The numbers of cells expressing COX-1 and COX-2 also rose upon zymosan injection and this correlated with the increasing activity of both isoforms. Interestingly, we indirectly detected that COX-1 and COX-2 expression occurred in the same leukocytes at the peak of inflammation. These findings confirm that not only COX-2, but also COX-1 plays an important role in inflammation and not only in physiological processes. The activity of the COXs was evaluated by their ability to catalyze the synthesis of their products: $e x$ vivo of oxidized TMPD by its peroxidase activity (see "COX activity assay") and in vivo by the production of prostaglandins $\mathrm{E}_{2}$ and $\mathrm{D}_{2}$. During the course of zymosan peritonitis, both COX activities were enhanced and even $24 \mathrm{~h}$ post-injection both were significantly elevated; however, COX-2 activity was stronger. This implies 
that the COXs are also involved in the resolution of peritonitis.

The second approach used to evaluate COX activity was the measurement of prostaglandin production in samples collected in situ at the inflammatory focus. The production of prostaglandins in this model has been the subject of numerous investigations. It was shown that $\mathrm{PGE}_{2}$ and $\mathrm{PGI}_{2}$ are produced very intensively within the first $45 \mathrm{~min}$ of zymosan application and, while the synthesis of the latter drops within half an hour, $\mathrm{PGE}_{2}$ is also synthesized at later time points (Doherty et al. 1985; Kolaczkowska et al. 2002; Rao et al. 1994). In contrast, to the best of our knowledge the production of anti-inflammatory $\mathrm{PGD}_{2}$ (precursor of the prostaglandin $\mathrm{J}$ series) has not yet been investigated in this model. In the current study, kinetic analyses revealed that $\mathrm{PGE}_{2}$ is produced in large amounts during the peak of inflammation, while $\mathrm{PGD}_{2}$ is synthesized during both the peak and the resolution phases of peritonitis. Thus COX activity, especially that of COX-2, during the late stages of peritonitis might be related to the high production of $\mathrm{PGD}_{2}$ at this time. These results correspond with those of studies on another model of acute inflammation, namely rat carrageenan-induced pleurisy (Gilroy et al. 1999; Gilroy et al. 1998).

The major goal of the current investigations was to verify the involvement of resident peritoneal leukocytes in $\mathrm{COX}$ activity and prostaglandin synthesis during zymosan peritoneal inflammation. The murine peritoneum contains macrophages, lymphocytes, and mast cells, with highest numbers of the first and lowest of the mast cells (Tchougounova et al. 2005). However, lymphocytes do not participate in zymosan peritonitis (Kolaczkowska et al. 2008b). The role of tissue-resident leukocytes was disregarded for a long time, but the cells play an important role not only in the initiation of inflammation, but also at later stages of the reaction. For example, at the onset and the peak of zymosan peritoneal inflammation, resident peritoneal macrophages and mast cells produce chemokines (Ajuebor et al. 1999) and MMP-9 (Kolaczkowska et al. 2007) that are critical for neutrophil infiltration into the peritoneum. The current study revealed that a lack of mast cells decreased COX activity (COX-1 at 6 and $24 \mathrm{~h}$ and COX-2 at $6 \mathrm{~h}$ ), but it had no significant impact on $\mathrm{PGE}_{2}$ and $\mathrm{PGD}_{2}$ production at those time points. However, it cannot be excluded that the decrease in COX activity in mice deprived of functional mast cells might be linked to the decreased neutrophil infiltration observed in these animals (Ajuebor et al. 1999) and not due to the high COX activity in resident mast cells. Nevertheless, as we showed in the current study, the basic COX-1 activity present in untreated peritoneal leukocytes can undoubtedly be attributed to mast cells. Furthermore, mast cells co-synthesize $\mathrm{PGE}_{2}$ and exclusively produce $\mathrm{PGD}_{2}$ in intact mice. This is not surprising, as $\mathrm{PGD}_{2}$ is the major COX product of mast cells (Ueno et al. 2008).

Moreover, the study showed that resident peritoneal macrophages carry out both COX activities at every stage of zymosan peritonitis. At the peak of inflammation, COX-1 and COX-2 of macrophage origin contribute to $\mathrm{PGE}_{2}$ synthesis and at the time of resolution also to $\mathrm{PGD}_{2}$ synthesis. In contrast to the removal of mast cells, it was shown that the elimination of resident peritoneal macrophages increases neutrophil accumulation at later stages of peritonitis and this was explained by the lack of production of antiinflammatory interleukin (IL)-10 synthesized by those cells (Ajuebor et al. 1999; Kolaczkowska et al. 2007). Therefore the down-regulation of COX activities and prostaglandin synthesis can indeed be attributed to the lack of resident peritoneal macrophages and thus indicates that it occurs in those cells during the whole course of peritonitis. Moreover, the current study shows that not only the lack of IL-10, but most probably also of $\mathrm{PGD}_{2}$ might be responsible for the prolonged presence of neutrophils in the peritoneum of mice depleted of resident peritoneal macrophages. In fact, the detection of such a strong involvement of resident peritoneal macrophages in the synthesis of $\mathrm{PGD}_{2}$ at $24 \mathrm{~h}$ of inflammation is the most striking discovery. It should be kept in mind that at this time point, inflammatory macrophages still arrive at the inflammatory focus (Kolaczkowska et al. 2001b) and it was assumed that these are the cells responsible for the production of anti-inflammatory prostaglandins.

In conclusion, we showed that fluctuations in the expression and activity of both COX isoforms accompany the course of acute inflammation. Most importantly, we showed that resident peritoneal mast cells and, especially, macrophages are important leukocyte types in which COX activity occurs. This COX activity is not limited to the early inflammatory stages, but is also critical for $\mathrm{PGD}_{2}$ production at the late resolution phase of inflammation.

Acknowledgment: This study was partially supported by DS/BiNoZ/IZ/773 and BW19a/2007 (for E. Kolaczkowska) from the Jagiellonian University.

\section{REFERENCES}

Ajuebor MN, Das AM, Virag L et al (1999) Role of resident peritoneal macrophages and mast cells in chemokine production and neutrophil migration in acute inflammation: evidence for an inhibitory loop involving endogenous IL-10. J Immunol 162:1685-1691

Das AM, Flower RJ, Perretti M (1997) Eotaxin-induced eosinophil migration in the peritoneal cavity of ovalbumin-sensitized mice: mechanism of action. J Immunol 159:1466-1473

Doherty NS, Poubelle P, Borgeat P et al (1985) Intraperitoneal injection of zymosan in mice induces pain, inflammation and the synthesis of peptidoleukotrienes and prostaglandin E2. Prostaglandins 30:769-789

Fu JY, Masferrer JL, Seibert K et al (1990) The induction and suppression of prostaglandin $\mathrm{H} 2$ synthase (cyclooxygenase) in human monocytes. J Biol Chem 265:16737-16740 
Gilroy DW, Colville-Nash PR, Willis D et al (1999) Inducible cyclooxygenase may have anti-inflammatory properties. Nat Med 5:698-701

Gilroy DW, Tomlinson A, Willoughby DA (1998) Differential effects of inhibitors of cyclooxygenase (cyclooxygenase 1 and cyclooxygenase 2) in acute inflammation. Eur J Pharmacol 355:211-217

Hamberg M, Samuelsson B (1973) Detection and isolation of an endoperoxide intermediate in prostaglandin biosynthesis. Proc Natl Acad Sci USA 70:899-903

Kolaczkowska E, Arnold B, Opdenakker G (2008a) Gelatinase B/MMP-9 as an inflammatory marker enzyme in mouse zymosan peritonitis: comparison of phase-specific and cell-specific production by mast cells, macrophages and neutrophils. Immunobiology 231:109-124

Kolaczkowska E, Barteczko M, Plytycz B et al (2008b) Role of lymphocytes in the course of murine zymosan-induced peritonitis. Inflamm Res 57:272-278

Kolaczkowska E, Chadzinska M, Scislowska-Czarnecka A et al (2006a) Gelatinase B/matrix metalloproteinase-9 contributes to cellular infiltration in a murine model of zymosan peritonitis. Immunobiology 211:137-148

Kolaczkowska E, Chadzinska M, Seljelid R et al (2001a) Strain differences in some immune parameters can be obscured by circadian variations and laboratory routines: studies of male C57BL/6J, Balb/c and CB6 F1 mice. Lab Anim 35:91-100

Kolaczkowska E, Lelito M, Kozakiewicz E et al (2007) Resident peritoneal leukocytes are important sources of MMP-9 during zymosan peritonitis: superior contribution of macrophages over mast cells. Immunol Lett 113:99-106

Kolaczkowska E, Plytycz B, Arnold B et al (2009) Increased cyclooxygenase activity impairs apoptosis of inflammatory neutrophils in mice lacking gelatinase $\mathrm{B} /$ matrix metalloproteinase-9. Immunology 128:e262-e274

Kolaczkowska E, Scislowska-Czarnecka A, Chadzinska M et al (2006b) Enhanced early vascular permeability in gelatinase B (MMP-9)-deficient mice: putative contribution of COX-1-derived PGE2 of macrophage origin. J Leukoc Biol 80:125-132

Kolaczkowska E, Seljelid R, Plytycz B (2001b) Role of mast cells in zymosan-induced peritoneal inflammation in $\mathrm{Balb} / \mathrm{c}$ and mast cell-deficient WBB6F1 mice. J Leukoc Biol 69:33-42

Kolaczkowska E, Shahzidi S, Seljelid R et al (2002) Early vascular permeability in murine experimental peritonitis is co-mediated by resident peritoneal macrophages and mast cells: crucial involvement of macrophage-derived cysteinylleukotrienes. Inflammation 26:61-71
Langenbach R, Morham SG, Tiano HF et al (1995) Prostaglandin synthase 1 gene disruption in mice reduces arachidonic acid-induced inflammation and indomethacin-induced gastric ulceration. Cell 83:483-492

Majno G, Joris I (2004) Cells, tissues, and disease: principles of general pathology. Blackwell, Oxford

Masferrer JL, Zweifel BS, Seibert K et al (1990) Selective regulation of cellular cyclooxygenase by dexamethasone and endotoxin in mice. J Clin Invest 86:1375-1379

Miller SB (2006) Prostaglandins in health and disease: an overview. Semin Arthritis Rheum 36:37-49

Morham SG, Langenbach R, Loftin CD et al (1995) Prostaglandin synthase 2 gene disruption causes severe renal pathology in the mouse. Cell 83:473-482

Rao TS, Currie JL, Shaffer AF et al (1994) In vivo characterization of zymosan-induced mouse peritoneal inflammation. J Pharmacol Exp Ther 269:917-925

Sheibanie AF, Yen JH, Khayrullina T et al (2007) The proinflammatory effect of prostaglandin E2 in experimental inflammatory bowel disease is mediated through the IL-23-> IL-17 axis. J Immunol 178:8138-8147

Simmons DL, Botting RM, Hla T (2004) Cyclooxygenase isozymes: the biology of prostaglandin synthesis and inhibition. Pharmacol Rev 56:387-437

Straus DS, Pascual G, Li M et al (2000) 15-deoxy-delta 12,14-prostaglandin J2 inhibits multiple steps in the NF-kappa B signaling pathway. Proc Natl Acad Sci USA 97:4844-4849

Tchougounova E, Lundequist A, Fajardo I et al (2005) A key role for mast cell chymase in the activation of pro-matrix metalloprotease-9 and pro-matrix metalloprotease-2. J Biol Chem 280:9291-9296

Ueno N, Taketomi Y, Koga K et al (2008) A negative regulator of delayed prostaglandin D2 production in mouse mast cells. Biochim Biophys Acta 1781:415-421

van Rooijen N, Sanders A (1994) Liposome mediated depletion of macrophages: mechanism of action, preparation of liposomes and applications. J Immunol Methods 174:83-93

Vane JR (1971) Inhibition of prostaglandin synthesis as a mechanism of action for aspirin-like drugs. Nat New Biol 231:232-235

Warner TD, Mitchell JA (2004) Cyclooxygenases: new forms, new inhibitors, and lessons from the clinic. FASEB J 18:790-804

Willoughby DA, Moore AR, Colville-Nash PR (2000) COX-1, COX-2, and COX-3 and the future treatment of chronic inflammatory disease. Lancet 355:646-648 